\title{
Uso de Aplicativos Educacionais - Experiências com Aprendizagem Criativa na Educação Básica
}

\author{
Graziela Ferreira Guarda ${ }^{1}$, Lídia Raquel Rocha Cunha ${ }^{1}$, Caroline dos Santos \\ Gonçalves ${ }^{1}$ \\ ${ }^{1}$ Departamento de Computação - Universidade Católica de Brasília (UCB) \\ Campus I - QS 07 - Lote 01 - EPCT - Águas Claras - Brasília - DF CEP: 71966-700. \\ grazielafguarda@gmail.com, lidiaraquelrocha@hotmail.com, \\ carolsantosg95egmail.com
}

\begin{abstract}
Creativity is an essential skill in the contemporary world, creative people are curious and like to explore ideas, so they tend to be innovative in solving problems. The literature has sought to find ways to encourage creativity in the classroom and presented fundamentals of Creative Learning, which tries to understand, experiment and characterize methodologies and learning environments capable of promoting creativity. In this sense, the article shows a methodological strategy for the teaching of logic of programming and logical reasoning with the use of Silent Teacher - Hour of Code and Scratch applications that were used for training and practice of exercises to compose the construction of knowledge based on the theory of the 4P's of Creative Learning in the school environment.
\end{abstract}

Resumo. A criatividade é uma habilidade essencial no mundo contemporâneo, pessoas criativas são curiosas e gostam de explorar ideias, por conta disso, tendem a serem inovadoras na resolução de problemas. A literatura tem buscado encontrar formas de incentivar a criatividade em sala de aula e apresentado fundamentos da Aprendizagem Criativa, que tenta entender, experimentar e caracterizar metodologias e ambientes de aprendizagem capazes de promover a criatividade. Neste sentido, o artigo mostra uma estratégia metodológica para o ensino de lógica de programação e raciocínio lógico com o uso dos aplicativos Silent Teacher - Hour of Code e Scratch que foram utilizados para treinamento e práticas de exercícios para compor a construção do conhecimento embasado pela teoria dos 4P's da Aprendizagem Criativa no âmbito escolar.

\section{Introdução}

Vivemos em um mundo que muda com uma velocidade constante. As crianças de hoje enfrentarão um fluxo contínuo de novos problemas e desafios inesperados no futuro, de modo que, muito do que elas aprendem hoje cairá em desuso amanhã. Deste modo, para se tornarem bem-sucedidas, elas deverão aprender a desenvolver soluções inovadoras para os problemas inesperados que surgirão. Neste sentido, sucesso e satisfação terão como base a capacidade de pensar e agir de maneira criativa pois o conhecimento por si só não será suficiente [Resnick 2006].

Alguns autores acreditam que esse novo paradigma é o da "Aprendizagem Criativa" [Iba \& Miyake 2010]. A Aprendizagem Criativa (AC) tem como propósito a criação de oportunidades educacionais que incentivam o desenvolvimento de produtos compartilháveis no mundo físico ou virtual, histórias, apresentações, instalações artísticas 
VIII Congresso Brasileiro de Informática na Educação (CBIE 2019)

Anais do XXV Workshop de Informática na Escola (WIE 2019)

e outros; o olhar para os interesses e paixões dos estudantes; a colaboração e o respeito mútuo; a exploração lúdica, a brincadeira e a percepção do erro não como um defeito, mas como uma tentativa que faz parte do processo de aprendizagem. [Carbajal \& Baranauskas 2018].

Nessa perspectiva é necessário ajudar os jovens a crescerem como pensadores criativos e as novas tecnologias de informação e comunicação podem contribuir muito na implementação de ambientes de AC, promovendo uma postura ativa dos estudantes, não como consumidores da informação, mas como seus próprios criadores. Neste contexto, pode ser destacado os aplicativos educacionais, como uma forma para motivar os estudantes a buscar, pesquisar, gerar novos conhecimentos, trabalhar de forma cooperativa como uma estratégia para manter o educando na escola, não por obrigação, mas por motivação.

Ademais, o ensino de conteúdos de computação para apoiar essa tendência é fundamental. Através da inclusão desses novos saberes, os estudantes tendem a compreender de forma mais completa o mundo e, consequentemente, poderão se tornar capazes de ter mais autonomia, flexibilidade, resiliência, pró-atividade e criatividade que são competências necessárias no mundo contemporâneo e a junção do uso dos aplicativos educativos para o ensino de conteúdos de computação vai em consonância com práticas já realizadas por muitos países [SBC 2017].

O presente experimento tem por objetivo mostrar uma estratégia metodológica para o ensino de lógica de programação e raciocínio lógico com o uso dos aplicativos Silent Teacher - Hour of Code e Scratch que foram utilizados para treinamento e práticas de exercícios para compor a construção do conhecimento embasado pela teoria dos 4P's da Aprendizagem Criativa - Projetos, Parcerias, Paixão e Pensar brincando [Resnick 2012].

O relato de experiência está dividido da seguinte maneira: a seguir, na Seção 2, é apresentada uma explicação sobre a metodologia utilizada, os aplicativos educativos utilizados e os exercícios desenvolvidos. Por fim, os resultados desta experiência serão destacados na Seção 4, de forma a concluir o propósito do estudo diante dos resultados já obtidos.

\section{Proposta e Metodologia}

A ideia do experimento surgiu oriundo do conjunto de atividades abordadas pelo projeto de pesquisa Logicamente como ferramenta para desenvolvimento do aprendizado. $\mathrm{O}$ projeto tem como enfoque desenvolver uma metodologia educacional e objetos de aprendizagem utilizando as premissas das aprendizagens criativas, pensamento computacional, cultura maker, computação desplugada e robótica educacional como pilares. O público-alvo foi uma turma mista com estudantes do $6^{\circ}$ e $7^{\circ}$ anos do Ensino Fundamental - Anos Finais de uma escola particular do Distrito Federal. Esse experimento foi aplicado como atividade introdutória para as demais atividades do ano do projeto em 2018.

O método utilizado neste trabalho se baseia na execução de um experimento que associa o uso dos aplicativos educacionais com a teoria dos 4P's da Aprendizagem Criativa [Resnick 2012]. As pesquisas do autor sobre AC consideram o princípio do aprender por toda a vida por meio de projetos e experiências permitindo aos estudantes explorar e deixar de lado as atividades estagnadas [Resnick 2006]. A teoria preza por 
VIII Congresso Brasileiro de Informática na Educação (CBIE 2019)

Anais do XXV Workshop de Informática na Escola (WIE 2019)

quatro conceitos fundamentais apresentados a seguir:

1. Projetos $-\mathrm{O}$ aprendizado se torna mais amplo quando os estudantes são inseridos em projetos significativos os quais se criam novas ideias, desenvolvem protótipos e refinam o trabalho por meio da repetição;

2. Parcerias - $\mathrm{O}$ aprendizado prospera quando é realizado como uma atividade social, com pessoas compartilhando ideias, colaborando em projetos e se ajudando mutuamente;

3. Paixão - Quando as pessoas trabalham em projetos pelas quais elas têm interesse, se trabalha mais tempo e se esforça mais, persiste diante os desafios e naturalmente aprendem mais nesse processo;

4. Pensar brincando - Aprender requer experiências divertidas, testar coisas novas, manipular diferentes materiais, testar limites, assumir riscos, repetir algo várias vezes.

Com base nessa teoria, é possível idealizar o "aprender fazendo" como uma possibilidade de resgatar o engajamento dos estudantes no processo de construção do conhecimento oriundo da Aprendizagem Criativa. Com a "mão na massa", participantes de experimentos se engajam na elaboração de invenções que dão visibilidade a ideias e a pensamentos e nessa perspectiva foi pensado uma forma para introduzir conteúdos introdutórios de lógica de programação. Deste modo, primeiramente foi aplicado um exercício para fins de diagnóstico para mapear se os estudantes possuíam algum conhecimento a respeito das seguintes temáticas: lógica matemática, proposições, conectivos lógicos (E, OU e NÃO) e conectivos de condição (Conjunção, Disjunção, Condicional e Comparadores).

A Tabela 1 abaixo demonstra as questões trabalhadas, bem como, as quantidades de acertos e erros cometidos pelos estudantes que participaram dessa etapa diagnóstica, bem como, os percentuais de acertos. Participaram dessa etapa 15 estudantes do projeto Logicamente.

Tabela 1. Exercício de Diagnóstico

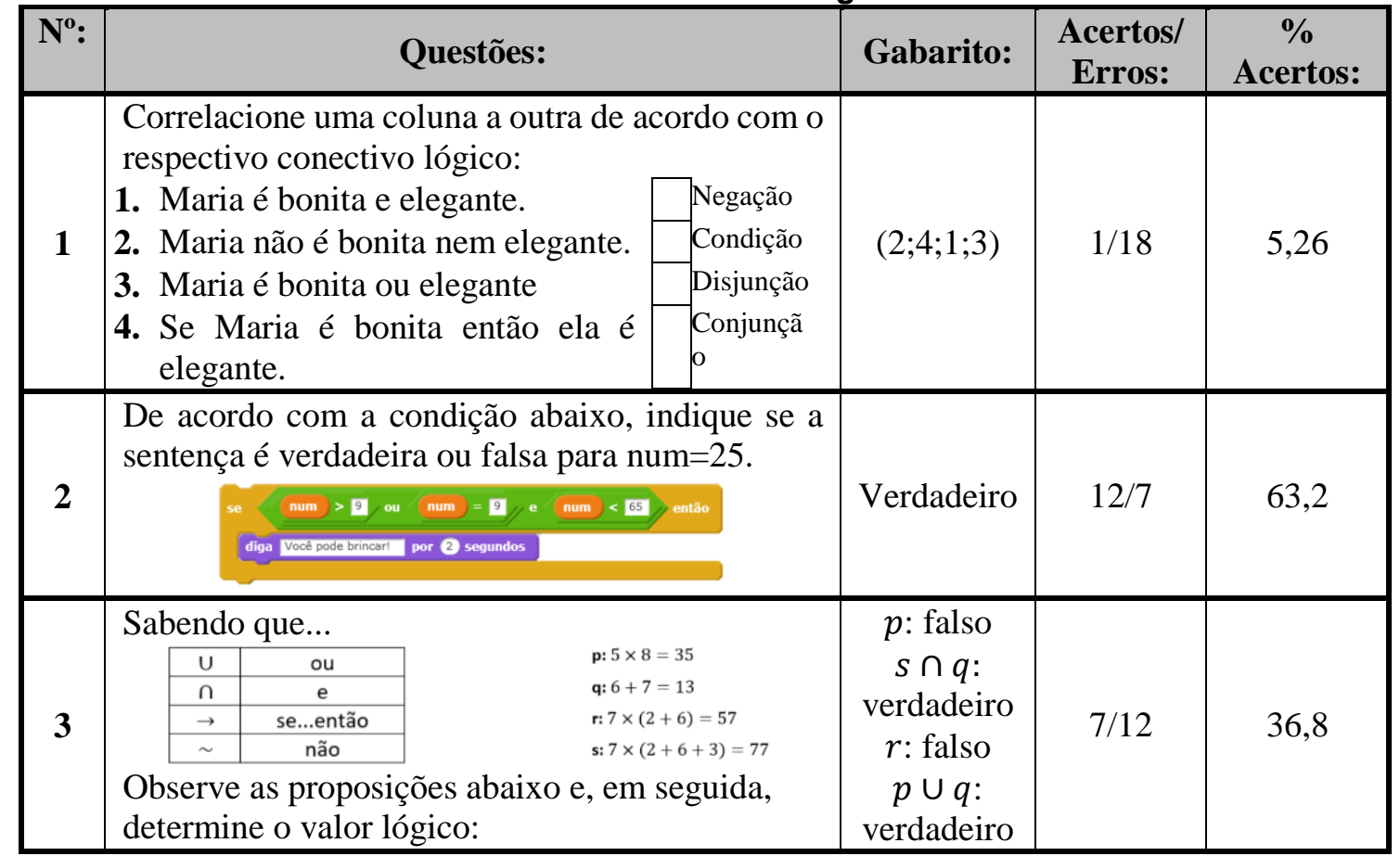


VIII Congresso Brasileiro de Informática na Educação (CBIE 2019)

Anais do XXV Workshop de Informática na Escola (WIE 2019)

\begin{tabular}{|c|c|c|c|c|}
\hline & $\boldsymbol{p} ; \boldsymbol{s} \cap \boldsymbol{q} ; \boldsymbol{r} ; \boldsymbol{p} \cup \boldsymbol{q}$ & & \\
\hline \multirow{4}{*}{4} & $\begin{array}{l}\text { Considere a afirmação: "Eu recebi o bolo e não } \\
\text { comi". Qual é a negação lógica dessa afirmação? } \\
\text { OBS: Lembre-se que a negação também modifica } \\
\text { o conectivo! }\end{array}$ & & & \\
& & & \\
& a) "Eu não recebi o bolo e não comi." & \multirow{2}{*}{ letra e } & \multirow{2}{*}{415} & \\
& b) "Eu recebi o bolo ou comi." & & \\
& c) "Eu não recebi o bolo e comi." & & \\
d) "Eu não recebi o bolo ou não comi." & & & \\
e) "Eu não recebi o bolo ou comi." & & & \\
\hline
\end{tabular}

De forma complementar, as questões 1 e 3 continham quatro itens cada e os índices de acertos foram mapeados separadamente como mostra a Tabela 2:

Tabela 2. Complementação dos Exercício de Diagnóstico

\begin{tabular}{|c|l|c|c|}
\hline Questão & \multicolumn{1}{|c|}{ Alternativas } & Acertos/Erros & \% Acertos \\
\hline \multirow{4}{*}{1} & Maria é bonita e elegante. & $8 / 11$ & $42,1 \%$ \\
\cline { 2 - 4 } & Maria não é bonita nem elegante. & $15 / 4$ & $78,9 \%$ \\
\cline { 2 - 4 } & Maria é bonita ou elegante & $7 / 12$ & $36,8 \%$ \\
\cline { 2 - 4 } & Se Maria é bonita então ela é elegante. & $5 / 14$ & $26,3 \%$ \\
\hline \multirow{3}{*}{3} & Linha 1: $p$ & $16 / 3$ & $84,2 \%$ \\
\cline { 2 - 4 } & Linha 2: $s \cap q$ & $14 / 5$ & $73,7 \%$ \\
\cline { 2 - 4 } & Linha 3: $r$ & $17 / 2$ & $89,5 \%$ \\
\cline { 2 - 4 } & Linha 4: $p \cup q$ & $9 / 10$ & $47,4 \%$ \\
\hline
\end{tabular}

Esse exercício diagnóstico foi de suma importância para que fosse possível mapear o conhecimento existente, bem como, para fins de organização dos conteúdos a serem trabalhados durante o ano. Os dados contidos na Tabela 1 demonstraram que em média os percentuais de acerto foram de $\mathbf{3 1 , 5 9 \%}$ que é uma média baixa, destacando a questão criada no Scratch com maior índice de acertos - 63,2\%.

\subsection{As atividades}

O propósito desse conjunto de atividades inicial foi trabalhar com os estudantes as temáticas: contextualização da aplicação dos conteúdos no mundo real; conceituações de: princípio da identidade, princípio da não-contradição, princípio do terceiro excluído; conectivos (negação, conjunção, disjunção e condicional); comparadores (maior que; menor que; igual a) e variáveis e tipos de dados. As atividades do projeto Logicamente ocorrem semanalmente com um encontro de 1 hora e 40 minutos de duração no contra turno durante o ano escolar e para aplicação dessas atividades iniciais foram realizados dois encontros.

\subsubsection{Primeiro encontro}

No primeiro encontro primeiramente foi feita uma aula para explicação dos seguintes conteúdos: o que é lógica e lógica matemática, exemplos práticos sobre proposições, comparadores e por fim, foi explicado o que são variáveis e os tipos de dados associados. Após isso, os estudantes foram expostos ao uso do aplicativo educativo Silent Teacher Hour of Code (Figura 1) que tem como propósito a realização de exercícios de variáveis. O aplicativo trabalha desde a criação de variáveis até operações entre elas com os tipos de dados primários: inteiro, real, lógico e caracteres. Os estudantes jogaram o Silent Teacher durante 30 minutos. 
VIII Congresso Brasileiro de Informática na Educação (CBIE 2019)

Anais do XXV Workshop de Informática na Escola (WIE 2019)

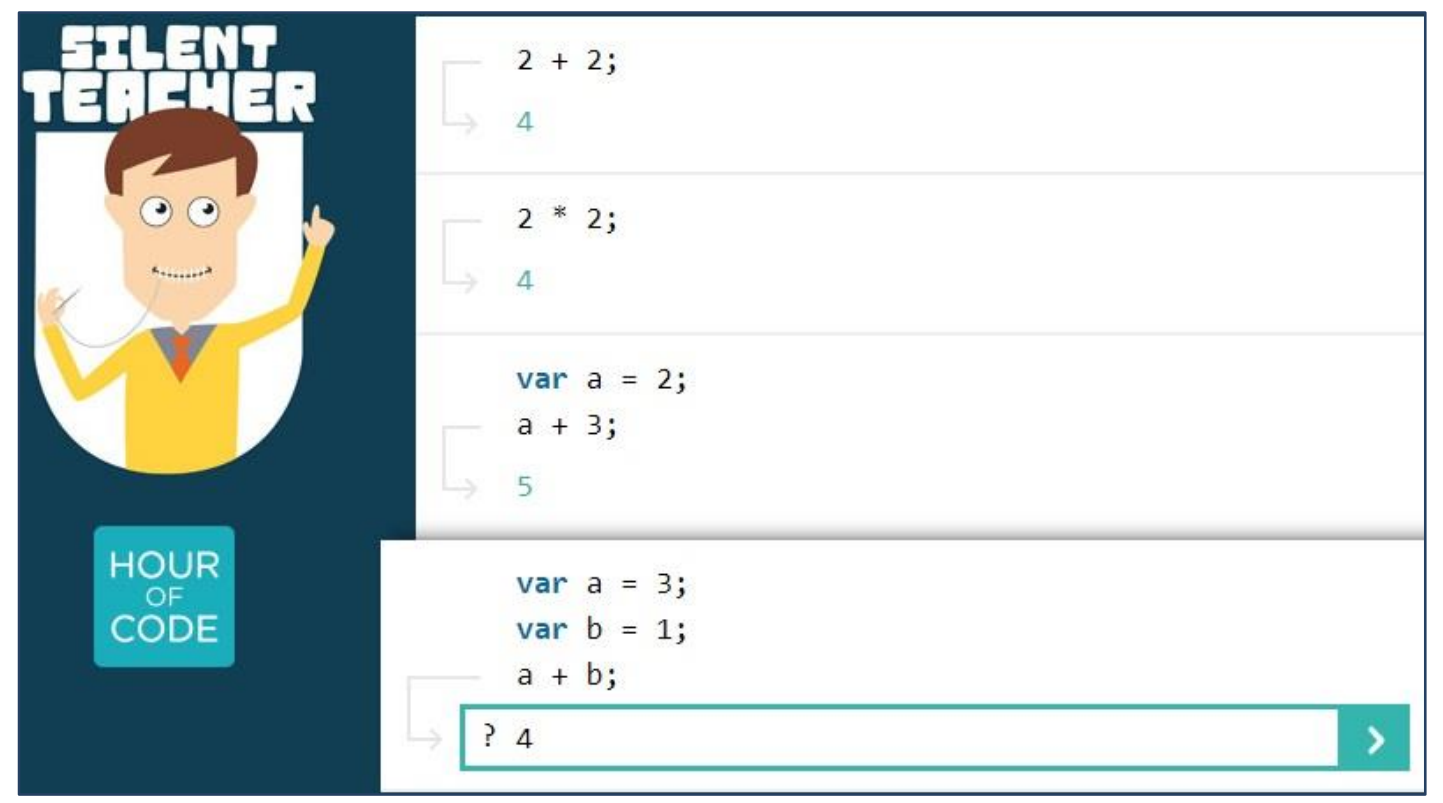

Figura 1. Exemplo de exercícios Silent Teacher-Hour of Code

Após o treino prático sobre variáveis foi disponibilizado aos estudantes um exercício para ser desenvolvido no Scratch, demonstrado na Tabela 3 a seguir:

Tabela 3. Exercícios Prático em Scratch - Encontro 1

\begin{tabular}{|c|c|}
\hline Questão: & Gabarito Esperado: \\
\hline $\begin{array}{l}\text { Objetivo: Fazer um } \\
\text { questionário que } \\
\text { compare } 3 \text { (três) } \\
\text { pessoas com idades } \\
\text { diferentes e informar } \\
\text { quem é o mais novo. } \\
\text { Dados de entrada: } \\
\text { nome; idade } \\
\text { Dados de saída: } \\
\text { nome (mais novo) }\end{array}$ & 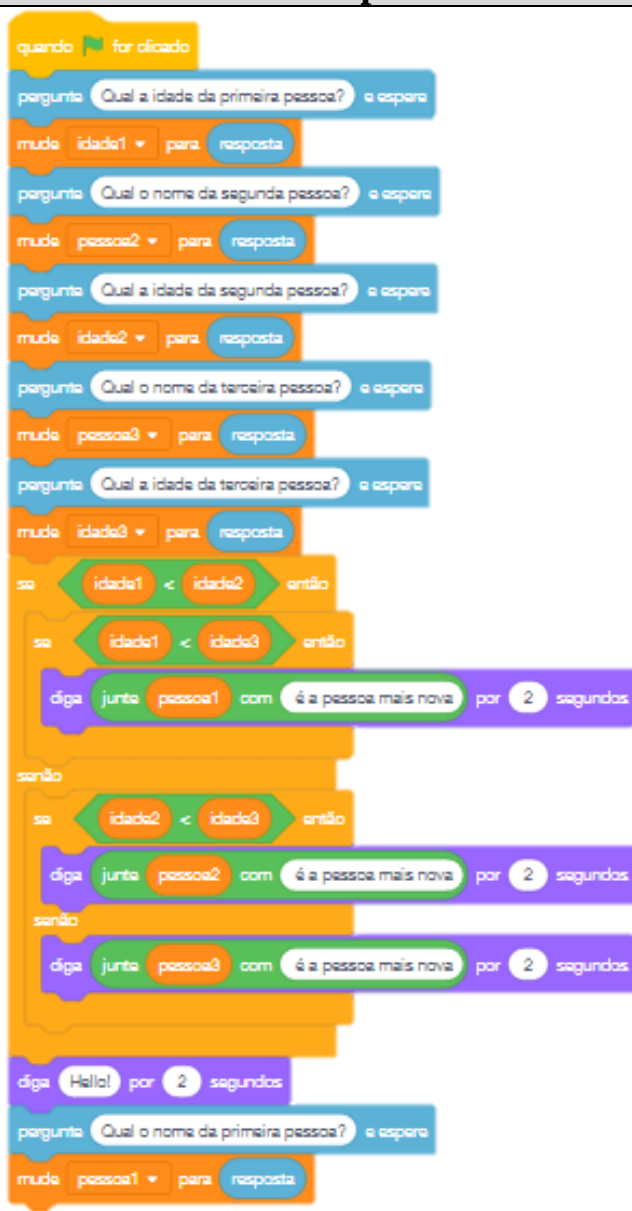 \\
\hline
\end{tabular}


VIII Congresso Brasileiro de Informática na Educação (CBIE 2019)

Anais do XXV Workshop de Informática na Escola (WIE 2019)

Os estudantes tiveram 40 minutos para realização do exercício no Scratch que reuniu todo o conteúdo ministrado no primeiro encontro e iniciou o uso de lógica de programação por blocos com os estudantes do projeto. Os projetos desenvolvidos pelos estudantes foram salvos e entregues individualmente para os monitores do projeto para correção e feedbacks que foram devolvidos e discutidos no encontro 2 - os feedbacks e os resultados serão mostrados na seção 3.

\subsubsection{Segundo encontro}

No segundo encontro foi realizada uma nova aula que foi iniciada recapitulando os conteúdos trabalhados no primeiro encontro e depois foram introduzidos os novos conteúdos que foram: os conectivos de conjunção, disjunção e negação. Após isso, foi mostrada uma tabela para os estudantes sinalizando aqueles que entregaram o projeto do encontro 1 e os que não entregaram.

Na sequência foi disponibilizado para os estudantes dois novos exercícios para serem desenvolvidos no Scratch com duração de 1 hora de aula para realização e entrega. Os exercícios estão expostos nas Tabelas 4 e 5 com seus respectivos gabaritos esperados:

Tabela 4. Exercícios Prático 1 em Scratch - Encontro 2

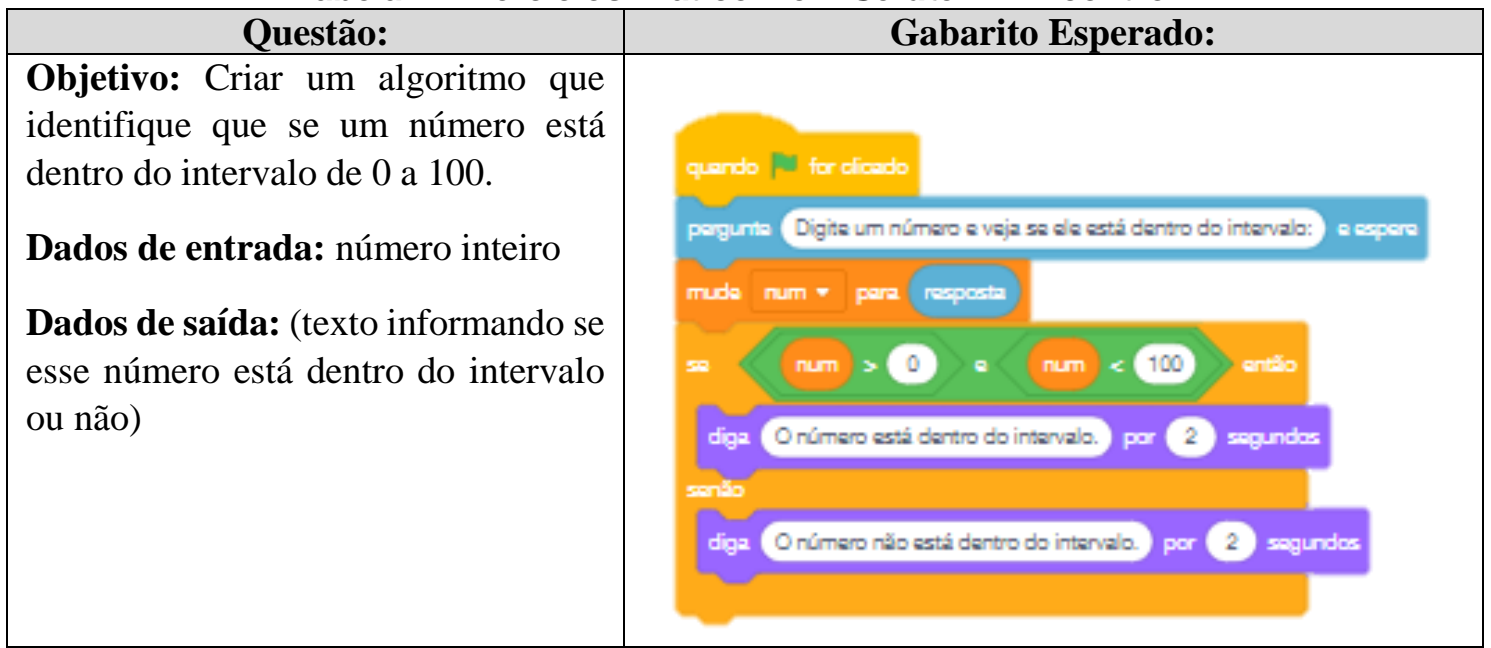

Tabela 5. Exercícios Prático 2 em Scratch - Encontro 2

\begin{tabular}{|c|c|}
\hline Questão: & Gabarito Esperado: \\
\hline \multirow{7}{*}{$\begin{array}{l}\text { Objetivo: Elaborar um questionário para } \\
\text { verifique se a pessoa tem idade e altura } \\
\text { para entrar em um brinquedo. } \\
\text { Dados de entrada: idade, altura } \\
\text { Dados de saída: texto informativo } \\
\text { mostrando se a pessoa está apta ou não } \\
\text { para usar o brinquedo. }\end{array}$} & \\
\hline & 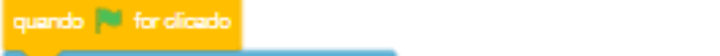 \\
\hline & pargunts Cual a sua idade? expase \\
\hline & mude idade 1. pare resposta \\
\hline & porgunte Cual a sua aturz? espare \\
\hline & mude alure 1- pars resposta \\
\hline & 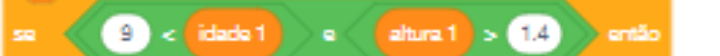 \\
\hline & dga (Vose pode brincar na Mantarha Plussal) por (2) sagundas \\
\hline & $\lim ^{+2}$ \\
\hline & 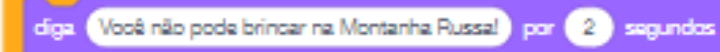 \\
\hline
\end{tabular}


VIII Congresso Brasileiro de Informática na Educação (CBIE 2019)

Anais do XXV Workshop de Informática na Escola (WIE 2019)

\section{Resultados e Discussões}

O conjunto de atividades e exercícios introdutórios do projeto Logicamente foi realizado com 1 (uma) turma do projeto, turma iniciante com estudantes do $6^{\circ}$ e $7^{\circ}$ anos. Essa turma foi composta por 21 estudantes, no entanto, nos três primeiros encontros nem todos estiveram presentes. Deste modo, a quantidade de estudantes participantes de cada encontro foi diferente. $\mathrm{Na}$ aula 1 que foi realizada a atividade diagnóstica, estiveram presentes 19 estudantes. Já no primeiro encontro (aula 2) estiveram presentes 10 estudantes - essa quantidade de ausências ocorreu devido a aula ter sido em uma véspera de feriado - e no segundo encontro (aula 3) estiveram presentes os 21 estudantes. Os resultados foram compilados considerando os resultados dos exercícios aplicados, bem como, as ponderações oriundas das correções dos mesmos.

\subsection{Resultados primeiro encontro}

Após a correção do exercício da Tabela 3 foi identificado que dos 10 estudantes que entregaram o projeto, 3 acertaram, o que representa um índice de acerto de $\mathbf{3 0 \%}$ que é um quantitativo baixo. De forma complementar, a Tabela 6 demonstra as ponderações referente à correção desses exercícios.

Tabela 6. Correção do exercício prático em Scratch - Encontro 1

\begin{tabular}{|c|c|}
\hline Estudante: & Observações: \\
\hline 1 & $\begin{array}{l}\text { Acertou o exercício. Adicionou um terceiro critério com a idade } 3 \text { e incluiu } \\
\text { efeitos interessantes. }\end{array}$ \\
\hline 2 & Não elaborou o algoritmo solicitado. \\
\hline 3 & $\begin{array}{l}\text { Não elaborou o algoritmo solicitado. Adicionou a fala em personagens } \\
\text { diferentes. }\end{array}$ \\
\hline 4 & $\begin{array}{l}\text { Não elaborou o algoritmo solicitado. Utilizou um dispositivo de início do } \\
\text { algoritmo diferente. }\end{array}$ \\
\hline 5 & $\begin{array}{l}\text { Solicitou as idades corretamente, mas não criou as variáveis certas, bem como, } \\
\text { a análise dos critérios. }\end{array}$ \\
\hline 6 & Elaborou corretamente o algoritmo e adicionou o terceiro critério de análise. \\
\hline 7 & $\begin{array}{l}\text { Acertou o exercício. Compreendeu a lógica. Criou um contexto para o algoritmo } \\
\text { solicitado e foi além, mostrou pessoa com idade mais velha. }\end{array}$ \\
\hline 8 & $\begin{array}{l}\text { Acertou a lógica, porém o resultado final ficou incorreto. Faltou mudar a } \\
\text { variável. }\end{array}$ \\
\hline 9 & $\begin{array}{l}\text { Coletou os dados e armazenou corretamente nas variáveis, mas não fez a } \\
\text { comparação entre as idades. }\end{array}$ \\
\hline 10 & Coletou metade dos dados. Não fez as comparações. \\
\hline
\end{tabular}

Os dados da Tabela 6 demonstram que os erros nos projetos entregues em parte foram decorrentes de pequenas falhas, como alguma condição que não foi atendida que são erros facilmente corrigíveis com o passar do tempo nas atividades do projeto. Por outro lado, alguns estudantes usaram recursos especiais da ferramenta, como efeitos de som e imagens. Em relação aos resultados dos exercícios aplicados no segundo encontro, os exercícios foram avaliados separadamente como segue: 
VIII Congresso Brasileiro de Informática na Educação (CBIE 2019)

Anais do XXV Workshop de Informática na Escola (WIE 2019)

Exercício 1 - segundo encontro (Tabela 4). Dos 21 projetos entregues, 9 estavam corretos e 11 incorretos, o que caracteriza um índice de acertos de $\mathbf{4 2 , 8 \%}$. Esse índice ainda é baixo, mas quando comparado com os índices de acerto do primeiro exercício (encontro 1), se percebe que houve uma melhora de rendimento por parte dos estudantes, outro indicador para esse baixo índice de acertos tem influência do número de ausências de estudantes no primeiro encontro, que perderam as explicações e práticas anteriores. A Tabela 7 demonstra as ponderações feitas aos projetos entregues - somente dos projetos com respostas incorretas:

Tabela 7. Correção do exercício prático 1 em Scratch - Encontro 2

\begin{tabular}{|c|l|}
\hline Estudante: & \multicolumn{1}{c|}{ Observações: } \\
\hline 1 & $\begin{array}{l}\text { Entendeu o conceito que foi explicado em sala, fez a questão corretamente, } \\
\text { só errou os sinais matemáticos que definem o intervalo. }\end{array}$ \\
\hline 2 & $\begin{array}{l}\text { Errou os sinais matemáticos mas adicionou fundo, trocou o personagem e } \\
\text { desenvolveu diálogos. }\end{array}$ \\
\hline 3 & Errou a comparação do intervalo, mas acertou a estrutura do algoritmo. \\
\hline 4 & Errou a comparação do intervalo, mas acertou a estrutura do algoritmo. \\
\hline 5 & $\begin{array}{l}\text { Entendeu o conceito que foi explicado em sala, desenvolveu parte da lógica } \\
\text { corretamente mas errou os sinais matemáticos que definem o intervalo. }\end{array}$ \\
\hline 6 & Errou a comparação do intervalo, mas acertou a estrutura do algoritmo. \\
\hline 7 & $\begin{array}{l}\text { Errou os sinais matemáticos mas utilizou o comando repita até para que } \\
\text { fosse encontrado um número dentro do intervalo. }\end{array}$ \\
\hline 8 & $\begin{array}{l}\text { Entendeu o conceito que foi explicado em sala, fez a questão corretamente, } \\
\text { só errou os sinais matemáticos que definem o intervalo. }\end{array}$ \\
\hline 9 & Errou a comparação do intervalo, mas acertou a estrutura do algoritmo. \\
\hline 10 & $\begin{array}{l}\text { Entendeu o conceito que foi explicado em sala, fez a questão corretamente, } \\
\text { só errou os sinais matemáticos que definem o intervalo. }\end{array}$ \\
\hline 11 & \begin{tabular}{l} 
Errou a comparação do intervalo, mas acertou a estrutura do algoritmo. \\
\hline
\end{tabular} \\
\hline
\end{tabular}

Os dados da Tabela 7 demonstram que os erros nos projetos entregues na maioria foram decorrentes de pequenas falhas, como inversão do operador "E" pelo "OU" ou erros nos sinais matemáticos (negativos, positivos) que são erros facilmente corrigíveis com o passar do tempo nas atividades do projeto. Por outro lado, se percebe uma evolução quanto ao uso das estruturas algorítmicas, especificamente no uso das estruturas condicionais (comando se, então, senão). Além do mais, parte dos estudantes começaram a utilizar recursos complementares do aplicativo como recursos de sons e imagens.

No exercício 2 - segundo encontro (Tabela 5). Dos 21 projetos entregues, 11 estavam corretos e 9 incorretos, o que caracteriza um índice de acertos de $\mathbf{5 2 , 4 \%}$. Esse índice é médio, mas demonstra novamente uma melhora de rendimento por parte dos estudantes o que torna possível inferir que os estudantes tendem a melhorar seu rendimento com a prática dos exercícios. Por fim, a Tabela 8 demonstra as correções feitas dos projetos entregues - somente dos projetos com gabaritos incorretos: 
VIII Congresso Brasileiro de Informática na Educação (CBIE 2019)

Anais do XXV Workshop de Informática na Escola (WIE 2019)

Tabela 8. Correção do exercício prático 2 em Scratch - Encontro 2

\begin{tabular}{|c|l|}
\hline Estudante: & \multicolumn{1}{c|}{ Observações: } \\
\hline 1 & $\begin{array}{l}\text { Esqueceu de adicionar o evento para iniciar o algoritmo mas fez a } \\
\text { atividade corretamente. }\end{array}$ \\
\hline 2 & Sintaxe correta. Uso do conectivo errado. \\
\hline 3 & Sintaxe correta. Uso do conectivo errado. \\
\hline 4 & Não concluiu a atividade. \\
\hline 5 & Sintaxe correta. Uso do conectivo errado. \\
\hline 6 & Sintaxe correta. Uso do conectivo errado. \\
\hline 7 & Não concluiu a atividade. \\
\hline 8 & Não concluiu a atividade. \\
\hline 9 & Sintaxe correta. Uso do conectivo errado. \\
\hline
\end{tabular}

Os dados da Tabela 8 demonstram que os erros nos projetos entregues foram concentrados na inversão do operador "E" pelo "OU" que são erros facilmente corrigíveis com o passar do tempo nas atividades do projeto. Por outro lado, se percebe uma evolução quanto ao uso das estruturas algorítmicas, especificamente no uso das estruturas condicionais (comando se, então, senão).

Considerando os resultados mapeados de forma geral, foi percebido que os estudantes não apresentaram dificuldades significativas quanto a construção dos algoritmos em bloco, mas apresentaram dificuldade em relação ao uso dos conectivos lógicos E, OU e NÃO. Esse indicativo foi muito importante para a definição das próximas atividades do projeto Logicamente. Como complemento, os estudantes ficaram em observação durante os três encontros relatados e dessas observações se pode destacar algumas considerações que foram classificadas como positivas e negativas da experiência realizada:

Aspectos positivos:

$\checkmark$ Em relação ao tempo disponível para os encontros, foi considerado suficiente, o tempo de aplicação dos exercícios também foi considerado suficiente, somente no exercício 2 do encontro 2 que houve problema, dos 21 estudantes, 3 não conseguiram finalizar o exercício;

$\checkmark$ Quanto à correção dos exercícios, foi possível identificar déficits de aprendizagem dos conteúdos abordados para fins de correção, a correção dos exercícios também foi considerada um aspecto positivo para que os estudantes pudessem compreender os erros;

$\checkmark$ O uso dos aplicativos foi recebido com muito entusiasmo pelos estudantes que não estavam habituados a ter aulas nesse formato pedagógico, nesse sentido se destaca a aplicação dos 4P's da aprendizagem criativa, especialmente o P do pensar brincando;

$\checkmark$ O uso de aplicativos gratuitos, dando a possibilidade aos estudantes de os utilizarem em casa sem geração de custos. 
VIII Congresso Brasileiro de Informática na Educação (CBIE 2019)

Anais do XXV Workshop de Informática na Escola (WIE 2019)

Aspectos negativos:

$\checkmark$ Dificuldade de aplicação dos operadores lógicos E, OU, NÃO nos exercícios.

$\checkmark$ Diante do entusiasmo das aulas em formato "mão na massa", os estudantes tiveram algumas dificuldades para se concentrar e houve muita conversa paralela, situação essa que o projeto buscou minimizar ao longo do ano.

\section{Considerações Finais}

O projeto Logicamente tem como finalidade motivar crianças e adolescentes a aprenderem conteúdos de computação que envolvem programação, lógica e assuntos relacionados de maneira criativa para ser possível formar cidadãos críticos e ativos em uma sociedade em constante transformação.

Os jogos, são uma atividade rica e de grande efeito que respondem às necessidades lúdicas, intelectuais e afetivas. Estimula a vida social e representa, uma contribuição significativa na aprendizagem. Através destes, crianças desenvolvem capacidades, conhecimentos, atitudes e habilidades, entre elas, se destacam: o favorecimento da mobilidade, a imaginação, a diversão, a aceitação de regras, o desenvolvimento do raciocínio lógico, entre outros. [Guarda et al. 2018].

A experiência aplicada para abordagem dos conteúdos iniciais do projeto foi considerada exitosa e possibilitou a equipe do projeto mapear indicativos que auxiliaram de forma significativa as ações e atividades futuras. Por fim, a experiência explicitou que a absorção dos conteúdos evoluem com o passar do tempo e que a prática foi gerando melhora nos índices de acerto dos exercícios aplicados.

\section{Referências Bibliográficas}

Carbajal, M.; Baranauskas C.; Programação, Robôs e Aprendizagem Criativa por meio de cenários: um estudo exploratório. In: XXIX Simpósio Brasileiro de Informática na Educação (SBIE 2018). DOI: http://dx.doi.org/10.5753/cbie.sbie.2018.1113.

Guarda, G.; Silva, D.; Goulart, I.; CriptoLab: Um game baseado em Computação Desplugada e Criptografia. In: Workshop sobre Educação em Computação (WEI), XXVI, 2018, Natal. Anais: Sociedade Brasileira de Computação - SBC, 2018. p. 49 59.

Iba, T., \& Miyake, T. (2010). Learning Patterns: a pattern language for creative learning II. In Proceedings of the 1st Asian Conference on Pattern Languages of Programs (p. 4). ACM.

Resnick, M. (2006). Computer as paint brush: Technology, play, and the creative society. Play and learning: How play motivates and enhances children's cognitive and socialemotional growth, 192-208.

Resnick, M (2012). Reviving Paper's Dream. In: Educational Technology, vol. 52, n 4, pp. 42-46.

Silent Teacher - Hour of Code. Jogo Digital Educacional. Toxicode (2018, março). Disponível em: http://silentteacher.toxicode.fr/hourofcode.

Sociedade Brasileira de Computação (2017) Diretrizes para Ensino de Computação na Educação Básica. http://www.sbc.org.br/documentos-da-sbc/send/131-curriculos-dereferencia/1177-diretrizes-para-ensino-de-computacao-na-educacao-basica, Agosto. 